\title{
A composição dos tribunais diocesanos na reforma dos processos de nulidade matrimonial
}

\author{
The Composition of the Diocesan Courts in the \\ Reform of the Nullity Proceedings
}

Felipe Fabiane ${ }^{1}$

Resumo: O Motu proprio Mitis Iudex Dominus Iesus propõe uma maior celeridade e acessibilidade nos processos de nulidade matrimonial aos fiéis. Tendo em conta que este objetivo muitas vezes é dificultado pela insuficiência de ministros qualificados para administrar a justiça, é oportuno refletir sobre o cânon 1673 do Motu Proprio. Tal cânon abre a possibilidade de que o tribunal seja composto em sua maioria por juízes leigos, bem como amplia as faculdades do Bispo seja de associarem-se a um tribunal vizinho, seja de confiarem as causas a um juiz único. $\mathrm{O}$ artigo reflete sobre as vantagens e desvantagens dos tribunais colegiais e monocráticos, dando prioridade à composição colegial. Nos casos de impossibilidade, podem-se confiar as causas a um juiz único, assistido por assessores. É importante promover a formação e a qualificação jurídica desses últimos, de modo que prestem um serviço de qualidade aos juízes.
Abstract: The Motu proprio Mitis Iudex Dominus Iesus proposes a greater speed and accessibility in the nullity processes of the marriage to the faithful. Given that this objective is often hampered by the insufficiency and the inadequacy of qualified ministers to administer justice, it is appropriate to reflect on canon 1673 of the Motu Proprio. This canon opens the possibility that the court will be mostly composed of lay judges, as well it expands the Bishop's faculties either to associate with a neighboring court or to entrust the case to a single judge. The article reflects on the advantages and disadvantages of collegiate and monocratic courts, giving priority to collegiate composition. In cases of impossibility, the case may be entrusted to a single judge, assisted by advisers. It is important to promote their training and legal qualification, so they can provide a qualified service to the judges.

Presbítero da Diocese de Guarapuava - PR, Bacharel em Filosofia pelo Instituto Sapientia de Francisco Beltrão e Bacharel em Teologia pela Faculdade Missioneira do Paraná, em Cascavel - PR. Mestre e Doutorando em Direito Canônico pela Pontifícia Universidade Lateranense de Roma. 
Palavras-Chaves: Tribunal, reforma processual, colégio judicante, juiz monocrático.
Keywords: Court, procedural reform, judiciary college, monocratic judge.

\section{Introdução}

A reforma proposta pela Carta Apostólica em forma de motu proprio Mitis Iudex Dominus Iesus insere-se no contexto da III Sessão Extraordinária e da XIV Assembleia Geral do Sínodo dos Bispos, encontros sinodais realizados em 2014 e 2015. Se se considera que o Sínodo refletiu sobre «os desafios pastorais da família no contexto da evangelização», a preocupação com as situações matrimoniais difíceis despertou uma importante reflexão do ponto de vista pastoral e jurídi$\mathrm{co}^{2}$.

As respostas dadas ao primeiro documento preparatório em 2014 demonstravam que a simplificação dos processos finalizados ao reconhecimento da nulidade do vínculo matrimonial era tida como uma necessidade ${ }^{3}$. A comissão especial instituída pelo Papa em agosto do mesmo ano tomou a sério as sugestões apresentadas e estudou uma proposta de reforma dos processos que tivesse em conta a maior acessibilidade e celeridade aos processos, sem sacrificar a segurança jurídica e o valor indissolúvel do matrimônio ${ }^{4}$.

No entanto, a busca de se adequar o processo canônico, de modo que se torne sempre mais rápido, simples e justo não é uma novidade. A recente reforma é uma intervenção eficaz que se insere na longa linha da tradição. A novidade maior, talvez, consista na finalidade notadamente pastoral da intervenção legislativa do Papa Francisco, que o leva a afirmar no Proemio do Motu Proprio: «O impulso reformador é alimentado pelo ingente número de fiéis que, embora desejando pro-

2 Cf. SynOdUs EPISCOPORUM, Os desafios pastorais sobre a familia no contexto da evangelização, Documento preparatório, $4, \mathrm{f}$.

3 Cf. SYNODUS EPISCOPORUM, Le sfide pastorali sulla famiglia nel contesto dell'evangelizzazione. Instrumentum laboris, n. 98.

4 Cf. R. R. CHACón, Antecedentes, estructura y valor jurídico en el sistema normativo canônico de los dos motu proprio de 15 agosto de 2015 y sus normas anejas in M. E. Olmos ORTEGA (ed.), Processos de nulidad matrimonial tras la reforma del Papa Francesco, Madrid 2016, 22. 
ver à sua própria consciência, muitas vezes foram afastados das estruturas jurídicas da Igreja por causa da distância física ou moral» ${ }^{5}$.

Revela-se, portanto, nas palavras do Pontífice que a Igreja sente necessidade de aproximar-se aos fiéis também com o instrumento que é o processo canônico que ajuda a verificar a verdade sobre o próprio matrimônio. A Igreja tem o grave dever de estar mais próxima e de dar a devida clareza aos seus fiéis sobre a própria situação de vida. Por outro lado, reconhece-se que, no atual contexto, os fiéis não têm possibilidade ou têm muita dificuldade em aceder às estruturas jurídicas eclesiásticas ${ }^{6}$.

O cardeal Francesco Coccopalmerio, falando sobre tal distância dos fiéis das estruturas da Igreja, distingue entre uma distância local e de uma distância temporal. A distância local, segundo o autor, consta de dois elementos, ou seja, do fato que os fiéis muitas vezes residem longe dos tribunais e não podem chegar à sua sede, e do fato que os mesmos não conhecem as estruturas jurídicas da Igreja. A distância temporal consiste na lentidão dos próprios procedimentos até a chegar à decisão sobre a nulidade ou menos dos matrimônios ${ }^{7}$, lentidão que faz com que o coração dos fiéis «seja longamente oprimido pelas trevas da dúvida» ${ }^{8}$.

A questão temporal dos processos sempre foi uma preocupação ao longo da tradição canônica. O Concílio de Trento, prescrevia uma duração não superior a dois anos das causas em primeira instância, disciplina que se repetiu no CIC 1917 (c. 1620). O Motu Proprio Causas Matrimoniales (1971) apresentava várias disposições para acelerar o curso dos juízos na Igreja, no que se refere ao exame das causas de nulidade matrimonial. A simplificação dos procedimentos no processo ordinário esteve na base da obra de revisão que portou à promulgação do CIC 1983, o qual prevê que as causas sejam resolvidas em no má-

5 FrANCISCUS PP., Litterae Apostolicae motu proprio datae quibus Canones Codicis Iuris Canonici de Causis ad Matrimonii nullitatem reformantur: Mitis Iudex, in $A A S$, CVII (2015), 958-970. Proemio).

6 Cf. F. Coccopalmerio, Processo matrimoniale e missione della Chiesa in Aa. Vv., La riforma del processo matrimoniale ad un anno dal Motu Proprio Mitis Iudex Dominus Iesus, Città del Vaticano 2017, 14.

7 Cf. F. COCCOPALMERIO, Processo matrimoniale, 14-15.

8 Cf. Franciscus PP., Mitis Iudex, Proemio. 
ximo um ano na primeira instância e em seis meses na segunda instância (c. 1453).

Um conhecido artigo de Gordon, publicado em 1969, expunha a preocupação com a clara duração excessiva de muitos processos matrimoniais em muitos tribunais, duração que excedia em vários anos os termos previstos no Codex. Entre as causas apontadas para o atraso e a duração excessiva dos juízos, o autor insiste sobre os seguintes aspectos: o defeito numérico de pessoal nos tribunais; a deficiente remuneração dos ministros; o despreparo de muitos juízes; a negligência das partes e dos colaboradores dos tribunais; o comportamento dilatório da parte dos advogados 9 .

Segundo Gordon, as principais causas dos problemas com a celeridade na justiça não devem ser atribuídas à forma do processo, em si, mas sim aos fatores que dependem das pessoas. Deste modo, mesmo que se abreviassem os procedimentos, tudo resultaria inútil se não se tivesse em conta as dificuldades de pessoal, de formação e de preparo dos ministros da justiça ${ }^{10}$. Não surpreende que à distância de quarenta anos do artigo de Gordon, Sabbarese insista sobre as mesmas causas para a excessiva duração dos processos de nulidade matrimonial: especialmente a inadequação do número de ministros no orgânico dos tribunais, a inadequada remuneração dos mesmos e a insuficiente preparação dos juízes ${ }^{11}$.

A proximidade local ou temporal, física ou moral em relação aos fiéis é o grande desafio que interpela a Igreja, a fim de que o serviço judiciário, como qualquer outra dimensão pastoral, seja marcado, sobretudo, pela caridade e pela misericórdia. Entendendo que tal desafio requer a «conversão das estruturas eclesiásticas», propomo-nos a refletir mais a fundo sobre o que o MIDI propõe a respeito da composição dos tribunais eclesiásticos. Tentaremos demonstrar como a almejada maior celeridade e simplicidade dos processos depende, diretamente, daqueles que são chamados a «afirmar a justiça».

9 Cf. I. Gordon, De nimia processuum matrimonialium duratione, in Periodica de re morali canonica liturgica, LVIII (1969), 500-506.

10 Cf. I. GORDON, De nimia processuum, 506.

11 Cf. L. SABBARESE, Semplicità e celerità nel processo matrimoniale canonico in P.A. BONNET - C. GULlo, Il giudizio di nullità matrimoniale dopo l'Istruzione “Dignitas Conubii”, Città del Vaticano 2007, 271-273. 


\section{A constituição dos tribunais diocesanos na reforma}

A reforma determinada pelo Motu Proprio Mitis Iudex Dominus Iesus tem como um dos seus aspectos mais significativos a centralidade do Bispo diocesano no serviço da justiça. As inovações normativas propostas pelo Papa são confiadas aos Bispos, porque, estes na qualidade de pastores das suas Igrejas particulares, possam chegar mais facilmente aos fiéis necessitados do serviço pastoral da justiça ${ }^{12}$.

Os instrumentos jurídicos oferecidos pelo MIDI aos Bispos para que realizem o intuito pastoral que está na base da reforma compreendem os mais diversos aspectos, desde o acompanhamento pastoral préjudicial, passando pela competência, organização e funcionamento dos tribunais, as mudanças procedimentais nas causas matrimoniais, até a previsão de um processo mais breve, de natureza extraordinária ${ }^{13}$.

Merece particular ênfase neste nosso escrito aquilo que se refere à organização e constituição dos tribunais de primeira instância para tratar das causas matrimoniais e que vem previsto através da normativa do cânon 1673 MIDI. A constituição de um tribunal para cada diocese é a condição que se requer para o efetivo funcionamento das novidades normativas no mecanismo processual, seja no que diz respeito ao processo ordinário ou ao processo mais breve. A renovação das estruturas judiciais é um dos meios mais efetivos para que se supere a distância física ou moral dos fiéis em relação ao serviço da justiça promovido pela Igreja ${ }^{14}$.

O §1 do cânon declara um princípio afirmado em modo unânime, tanto pelo CIC 1917, como pelo CIC 1983 com relação ao Bispo que constitui o tribunal diocesano em primeira pessoa considerando-se o seu poder próprio de julgar os fiéis. O Bispo é considerado o juiz de

12 Cf. A. W. Bunge, Presentación del nuevo proceso matrimonial, in URL: <http: //www.awbunge.com. ar/AADC2015.pdf>, 4 (in 01/04/2019).

13 A respeito da responsabilidade dos Bispos na concretização da reforma afirma Del Pozzo que estes são os responsáveis diretos por atuar a reforma, o que requer o próprio empenho pessoal acompanhado da preocupação pela qualidade do serviço judiciário proposto. (Cf. M. DEL Pozzo, Chiarimenti pontifici sul "processus brevior". Riflessione alla luce del Discorso del 25 novembre 2017 in Ius Canonicum, LVIII [2018], 532-533).

14 Cf. A. W. Bunge, Presentación del nuevo proceso, 7-8. 
primeira instância para todas as causas matrimoniais e pode exercer tal poder por si mesmo ou por outros de acordo com o direito ${ }^{15}$.

Um dos critérios fundamentais da reforma dos processos consiste na afirmação de que «o próprio Bispo é juiz». Como pastor e juiz nato da própria Igreja particular o Bispo diocesano pode exercitar a potestade judicial em primeira pessoa. Trata-se da afirmação de um aspecto fundamental que vinha se tornando meramente formal em função da recomendação de que o Bispo não julgasse pessoalmente por razões de oportunidade, e que o exercício da função judicial fosse quase sempre confiado ao próprio Vigário judicial ${ }^{16}$.

Ora, os critérios da reforma expressamente requerem que o Bispo exercite pessoalmente a função de juiz, em particular nos processos mais breves, mas não se exclui que isso possa realizar-se nos outros processos de nulidade matrimonial ${ }^{17}$. Trata-se de uma viva demonstração da proximidade e atenção pastoral aos fiéis, especialmente, nos serviços que se prestam à família. Na ratio que subjaz o MIDI, o serviço judicial é um serviço marcado essencialmente pela pastoralida$\mathrm{de}^{18}$.

A reafirmação da potestade judicial do Bispo diocesano se de um lado confere a este último maiores atribuições, de outro deve fazer recordar que a sua responsabilidade não se traduz na maior parte dos casos no exercício direto da função de julgar. Continua válida a sugestão de se evitar a implicação pessoal do Bispo quando estão em causa direitos controversos ou conflitos mais graves, protegendo a sua missão pastoral ${ }^{19}$.

15 Franciscus, PP., Mitis Iudex, can. 1673.

16 Cf. M. DEL Pozzo, L'organizzazione giudiziaria alla luce del m.p. "Mitis Iudex" in Stato, Chiese e pluralismo confessionale, XXXVI [2015], 8-9.

17 Cf. E. ZANETTI, Il ruolo del vescovo diocesano in REDAZIONE DEI QUADERNI DI DIRITTO ECCLESIALE (cur.), La riforma dei processi matrimoniali di Papa Francesco. Una guida per tutti, Milano 2016, 96-97.

18 Cf. P. V. PINTO, La riforma del processo matrimoniale per la dichiarazione di nullità voluta e decisa da Papa Francesco in Quaderni dello studio rotale XXIII (2016), 59-60.

19 Cf. M. J. Arroba CONDE, Presentazione dell' "Istruzione" della Congregazione per l'Educazione Cattolica: Gli studi di Diritto Canonico alla luce della riforma del processo matrimoniale, Città del Vaticano 2018, 30-31. 
A revalorização da função do Bispo nas causas de nulidade matrimonial compreende a sua responsabilidade na constituição e na manutenção dos ofícios com os quais se possa oferecer o serviço da justiça aos que dela necessitam. Por isso, continua válida a recomendação e o direito a que este forme o próprio tribunal diocesano, como afirma expressamente o $\S 2$ do cânon $1673 \mathrm{MIDI}^{20}$.

A constituição do tribunal diocesano constitui o referencial exemplar, como objetivo da justiça eclesiástica, segundo o MIDI. Deve-se constituir um tribunal que favoreça a proximidade entre os fiéis e o próprio Bispo na sua função de juiz, ou entre os fiéis e os juízes nos seus ofícios. A sua estruturação deve ser os critérios de reorganização necessária do aparato judiciário eclesiástico, que deve ter a Igreja particular como seu ponto de referência ${ }^{21}$.

\subsection{Os tribunais interdiocesanos e o tribunal mais próximo na reforma}

O fato de que cada Bispo deva constituir em sua diocese o tribunal de primeira instância, já vinha previsto tanto no CIC 1917 e no CIC 1983. Na prática, porém, com a possibilidade dada pelo cânon 1423 CIC 1983 a que vários Bispos constituíssem os tribunais interdiocesanos para remediar a falta de meios nas dioceses singulares tornou-se a regra predominante em muitos lugares do mundo. O Motu proprio, todavia, propõe o retorno à centralidade forma mais clássica de jurisdição que é a diocese, favorecendo os critérios de proximidade, e acessibilidade das estruturas eclesiásticas em relação aos próprios fiéis $^{22}$.

A reforma reconhece, implicitamente, que os motivos que levaram à constituição dos tribunais interdiocesanos em muitas regiões do mundo, hoje não são mais respondentes à realidade. Tinha-se em mente que tais tribunais seriam oportunos para assegurar que os fiéis tives-

FrANCISCUS PP., Mitis Iudex, can. 1673.

21 Cf. M. DEL Pozzo, L'organizzazione giudiziaria, 4 e 10.

22 Cf. A. W. Bunge, Presentación del nuovo proceso, 8; M. DEL Pozzo, L'organizzazione giudiziaria, 10. 
sem uma administração da justiça pronta, certa e acessível ${ }^{23}$. Nas dioceses isoladamente faltavam sacerdotes idôneos e formados a exercitarem este ministério com dedicação prioritária. No entanto, a concentração e acumulação de causas nos tribunais interdiocesanos, foi tornando os juízos sempre menos céleres e tais estruturas sempre mais inacessíveis ${ }^{24}$.

São pertinentes os dados apresentados por Bunge, em 2015, sobre a realidade argentina onde existiam apenas oito tribunais interdiocesanos de primeira instância e um tribunal da Conferência episcopal para a segunda instância. O próprio Papa Francisco, recebendo os participantes do Curso Super rato realizado pela Rota Romana em 2014, considerava pouco provável que as pessoas simples pudessem chegar até tribunal de Buenos Aires que na época contava com quinze dioceses, a mais distante a $240 \mathrm{~km}$ de distância ${ }^{25}$. Tal realidade, segundo Bunge, é comum a muitos países da América Latina e mesmo da Europa $^{26}$.

A situação atual levou o Santo Padre a impulsionar a criação dos tribunais diocesanos, no intuito pastoral, visando oferecer a concreta proximidade do serviço da justiça. Com isso, de um lado as Conferências episcopais são chamadas a respeitarem absolutamente o direito dos Bispos de organizarem a potestade judicial na própria Igreja particular $^{27}$. De outro lado, sublinha-se no MIDI o direito de recesso dos Bispos do tribunal interdiocesano sem necessidade da autorização da Sede Apostólica ${ }^{28}$.

23 «Unica solutio pro illis nationibus ubi exiguus sit numerus clericorum, in iure canonico peritorum, et in hoc discrimine hodie omnes inveniuntur nationes, est nova ordinario tribunalium, erectione, e.gr. tribunalium regionalium». (R. RoDRIGO, Cur Optata A.M.P. "Causas matrimoniales" celeritas haud semper obtinetur?, in Periodica de re morali canonica liturgica, LXII [1973], 540).

Cf. F. RAmos, I tribunali ecclesiastici. Costituzione, organizzazione, norme processuali, Roma 1996, 119.

Cf. Franciscus PP., Saluto del Santo Padre Francisco ai partecipanti al Corso Super rato promosso dal Tribunale della Rota Romana (5 novembre 2014), in Quaderni dello Studio Rotale XXII (2015), 61-62.

26 Cf. A. W. Bunge, Presentación del nuevo proceso, 8.

27 Franciscus, PP., Mitis Iudex, Proemio.

28 Franciscus PP., Mitis Iudex, art. 8 RP. 
Deve-se esclarecer, contudo, que o Motu proprio ainda que não preveja a criação dos tribunais interdiocesanos, todavia não os abole e a estes reconhece plena vigência e operacionalidade, como se deduz da menção feita no próprio cânon 1673 §2, assim como dos artigos 11, 16 e 19 da Ratio procedendi. Ainda que haja um favor endereçado à constituição de novos tribunais diocesanos, é legítimo admitir realisticamente que, enquanto isso não for possível ou oportuno, mantém-se a continuidade dos órgãos já constituídos.

Estando ainda no texto normativo do MIDI, o parágrafo citado do cânon 1673 afirma que é facultado aos Bispos de aceder a outro tribunal «mais próximo», para o exame das próprias causas matrimoniais. Esta possibilidade também não consiste em uma novidade no Motu proprio. Embora não fosse uma hipótese prevista especificamente no CIC 1983, a instrução Dignitas Conubii dispunha o seguinte no art. 24 que o Bispo diocesano poderia pedir a Assinatura Apostólica a prorrogação de competência em favor de um tribunal vizinho, com o consentimento do bispo moderador deste tribunal ${ }^{29}$.

Na Dignitas Conubii não se propõe a criação de um novo tribunal, como que intermediário entre o tribunal diocesano ou aquele interdiocesano. $\mathrm{O}$ tribunal vicinum constitui, na realidade, uma situação subordinada à necessidade de tutela judicial dos direitos dos fiéis em cada diocese, mesmo naquelas desprovidas de pessoal competente: a competência territorial dada em modo momentâneo a outro tribunal diocesano próximo supre a necessidade de certas dioceses ${ }^{30}$.

Entre os pressupostos em relação aos quais a concessão da prorroga de competência é concedida pela Assinatura Apostólica, está a situação de impossibilidade e não de simples dificuldade na constituição de um tribunal local. Trata-se de uma necessidade operativa, e não uma escolha ou uma opção. Outro pressuposto é o consenso prévio do Bispo moderador do tribunal ao qual se deseja aceder. Enfim, requer-

29 PonTIFICIUM CONSILIUM PRO LEGUM TEXTIBUS, Instructio servanda a Tribunalibus dioecesanis et interdioecesanis pertractandis Causis Nullitatis Matrimonii: Dignitas Conubii, in Communicationes, XXXVII (2005), 11-92, art. 24.

30 Cf. M. DEL Pozzo, Dal "Tribunale limitrofo" al "tribunale sussidiario": una proposta di miglior sistemazione concettuale della nozione in J. KOWAL - J. LLOBEL (curr.), "Iustitia et iudicium». Studi di diritto matrimoniale e processuale canonico in onore di A. Stankiewicz, Città del Vaticano 2010, 1627-1628. 
se a intervenção da Suprema Autoridade, que verifica as condições para que se dê tal acordo. Fundamental, é a responsabilidade do Bispo requerente, que ao renunciar momentaneamente à função judicial na própria circunscrição, não pode desinteressar-se da questão, tampouco deixar de remediar tal situação provisória ${ }^{31}$.

O texto do cânon 1673 MIDI diverge em parte do art. 24 Dignitas Conubii, no sentido que não se apresenta o termo tribunal vicinum, mas sim, tribunal vicinius, fazendo supor um maior critério de proximidade do tribunal a que se deve aceder. Não é, todavia, claro, se esta proximidade deva se referir necessariamente à contiguidade material ou geográfica. $\mathrm{O}$ espírito da norma, que prevê não só a possibilidade de se aceder a um tribunal diocesano, mas também a um interdiocesano, supõe que o critério seja baseado na vizinhança ou maior acessibilidade do tribunal de destino, de modo a favorecer o bem dos fiéis da diocese de origem ${ }^{32}$.

Uma dúvida pertinente na nova norma se refere aos pressupostos para que o Bispo aceda ao tribunal «mais próximo», ou seja, se ainda é necessário que se constate uma situação de impossibilidade em se constituir o próprio tribunal diocesano. A formulação do cânon supõe uma escolha da parte do Bispo em fazer uso desta possibilidade, para facilitar o acesso dos seus fiéis ao tribunal. Todavia, parece recomendável que seja ainda hipótese excepcional ou temporária, pois prevalece no MIDI a obrigação do Bispo de constituir o tribunal na própria diocese ${ }^{33}$.

\subsection{A constituição dos órgãos judicantes na reforma}

A constituição dos órgãos judicantes ${ }^{34}$ segundo a normativa do Motu Proprio contém elementos importantes seja de continuidade,

31 Cf. M. DEL Pozzo, Dal “Tribunale limitrofo”, 1629-1631.

32 Cf. M. DEL Pozzo, L'organizzazione giudiziaria, 17.

33 Cf. C. PEÑA GARCÍA, El proceso ordinario de nulidad matrimonial en la nueva regulación procesal, in M. E. Olmos ORTEGA (ed.), Processos de nulidad matrimonial tras la reforma del Papa Francesco, Madrid 2016, 92; M. DEL Pozzo, L'organizzazione giudiziaria, 17-18.

34 O texto do Motu Proprio fale na possibilidade dada aos Bispos de confiar as causas seja a um "tribunal colegial" ou a um "tribunal" formado por um juiz único. 
como de descontinuidade com a normativa precedente. Nos $\S 3$ e 4 do cânon 1673 MIDI vem ampliada a possibilidade da constituição de um órgão judicante formado por um juiz único para tratar das causas matrimoniais. A reforma, contudo, mantém a predileção pela colegialidade, como resulta da norma segundo a qual as causas de nulidade de matrimônio são reservadas a um colégio de três juízes. O mesmo deve ser presidido por um juiz clérigo, os restantes juízes podem ser também leigos ${ }^{35}$.

A colegialidade continua sendo a modalidade ordinária de juízo para as causas matrimoniais em primeira instância e, segundo o $§ 5$ do mesmo cânon do MIDI, será obrigatória para o exame das causas em segunda instância. Tais normas, porém, não podem ser separadas daquilo que prevê o $\S 4$, que aumenta a possibilidade de derroga do juízo colegial para as causas matrimoniais, conforme as necessidades ou circunstâncias locais ${ }^{36}$.

Como se depreende da norma, a faculdade de nomear um juiz único para tratar das causas matrimoniais nos casos de impossibilidade de formar o colégio, deixa de depender da autorização preventiva e do controle das Conferências episcopais, como previa o cânon 1525 $\S 4$. No MIDI, a constituição do órgão judicante em primeira instância é confiada à responsabilidade do Bispo, o garante do exercício do poder judicial na própria diocese, sempre com o cuidado de que este não permita nenhum tipo de laxismo ${ }^{37}$. Isto significa que o fato de as causas matrimoniais poderem ser julgadas muitas vezes por um único juiz não deve implicar na leviandade, nem mesmo na superficialidade dos juízos.

O texto normativo do MIDI evidencia alguns elementos de fundamental importância que motivaram um intenso debate na revisão do direito processual, em vista de tornar os processos mais céleres e acessíveis. Nos pontos subsequentes, centraremos a nossa pesquisa em três

Preferimos, no entanto, não adotar tal termo neste contexto, para que se diferencie o "tribunal" enquanto estrutura judiciária, do "órgão judicante", enquanto o turno ou juiz único a quem se confiam cada uma das causas. Verificar a conclusão do artigo.

35 FRANCISCUS PP., Mitis Iudex, can. $1673 \S 3$.

36 Franciscus PP., Mitis Iudex, can. 1673 §4.

37 Franciscus PP., Mitis Iudex, Proemio. 
temas específicos: a questão do laicato e a função judicial, com as suas consequências para a composição do colégio judicante; um confronto entre os juízos colegiais e os juízos monocráticos, tendo em vista a decisão final do processo; a preparação dos ministros, particularmente dos assessores do juiz único.

\section{Os órgãos judicantes e os leigos como juízes}

O §3 do cânon 1673 do MIDI porta consigo uma novidade significativa para o exame das causas matrimoniais, em relação aos processos em geral (c. 1421 §2): para tais causas, será possível ao Bispo nomear não apenas um juiz leigo para integrar o colégio judicante em caso de necessidade, mas sim, nomear dois juízes leigos, ao lado do presidente clérigo. A permissão da Conferência episcopal não será mais necessária para que se constituam tais juízes. Trata-se de uma abertura significativa não apenas para facilitar a constituição dos tribunais colegiais, como para valorizar o papel dos leigos, que, agora podem exercer a pleno título a função judicial e ser maioria na composição do colégio ${ }^{38}$.

As intervenções normativas visando a inclusão dos leigos na cooperação com o poder judicial na Igreja foram dados em modo progressivo depois do Concílio Vaticano II e ao longo da obra de revisão do CIC. A questão é ainda aberta, pois persistem divergências doutrinais: o tema tem como plano de fundo jurídico a problemática da fonte sacramental ou menos do poder de governo, bem como a legitimidade a exercer os ofícios eclesiásticos ${ }^{39}$.

A Constituição Dogmática Lumen Gentium dedicou o quarto capítulo ao tema dos leigos, depois de ter declarado as diversas funções da hierarquia. Quanto ao conceito de leigos são definidos como os fiéis incorporados a Cristo pelo Batismo que exercem, na parte que lhes toca, a missão de todo o povo cristão na Igreja ${ }^{40}$. Tais fiéis, em força

38 Cf. C. PEÑA GARCía, El proceso ordinario de nulidad, 92-93.

39 Cf. E. Kouveglo, I fedeli laici e l'esercizio della potestà nella Chiesa. Status quaestionis e ricerca di una chiave funzionale di lettura, in Apollinaris, LXXXX (2017), 209-210.

40 Cf. Concilium Oecumenicum Vaticanum II, Costitutio dogmatica de Ecclesia: Lumen Gentium, in AAS, LVII (1965), 5-75, n. 31. 
da participação ao tríplice múnus sacerdotal, profético e real de Cristo, participam da missão no âmbito secular, mas também em outros âmbitos da vida eclesial ${ }^{41}$. No n. 33, Lumen Gentium afirma que os fiéis leigos podem ser chamados a uma colaboração imediata ao apostolado dos ministros ordenados e a exercer certos ofícios eclesiásticos com finalidade espiritual ${ }^{42}$.

No período imediatamente pós-conciliar, o trabalho da Pontifícia Comissão para a revisão do CIC e vários outros autores procuram aprofundar teologicamente e juridicamente as afirmações conciliares. Ao mesmo tempo, as emanações normativas de Paulo VI procuravam abrir aos leigos espaços até agora a eles preclusos, como alguns ministérios e ofícios qualificados em âmbito litúrgico e o ofício de juiz, integrando o colégio judicante ${ }^{43}$.

A instituição do juiz leigo pelo Motu Proprio Causas matrimoniales de 1971 suscitou um amplo debate sobre a possibilidade da participação laical em ofícios relacionados ao governo na Igreja. Um dos princípios conciliares afirma que os Bispos detêm o poder sagrado em função da qual, exercem o governo nas suas Igrejas particulares, na qual se inclui a função judicante, além da função executiva e legislativa (LG 27). A expressão «sacra potestas» deixava presumir a origem sacramental de toda potestade na Igreja. Porém, vários autores visando atribuir maiores espaços de participação aos leigos, teorizavam a distinção entre a potestade de Ordem e a potestade de jurisdição, com origens distintas 44 .

Para os que defendiam que o poder de jurisdição na Igreja provinha unicamente do sacramento da Ordem, ficava exclusa a possibilidade que um leigo pudesse ser sujeito do poder de governo: esta seria transmitida somente a quem fosse constituído clérigo. $\mathrm{O}$ fato de $\mathrm{o}$ Motu Proprio de Paulo VI ter admitido os leigos a fazerem parte do colégio judicante deveria ser entendido em modo completamente excepcional, em caráter de mera suplência. Na sentença de nulidade sen-

41 Cf. C. IZZI, Identità e ruolo dei laici nella comunione ecclesiale in GRUPPO ITALIANO DOCENTI DI DIRITTO CANONICO (CUR.), La comunione nella vita della Chiesa: le prospettive emergenti del Vaticano II, Milano 2015, 216.

42 Cf. Concilium Oecumenicum Vaticanum II, Lumen Gentium, n. 33.

43 Cf. C. IzZI, Identità e ruolo dei laici, 220.

44 Cf. E. Kouveglo, I fedeli laici, 211-212. 
do meramente declarativa, o leigo participa da decisão limitando-se a declarar um fato, uma vez que tal sentença não há caráter constituti$\mathrm{vo}^{45}$.

Havia, no entanto, uma corrente de pensamento que afirmava que o poder de jurisdição tinha uma origem diversa do sacramento da Ordem. Assim, resultavam distintas duas formas de poder, a potestas ordinis, relacionada à função sacramental e a potestas iurisdictionis relacionada ao governo. Esta tinha como fonte o mandato canônico recebido da legítima autoridade. Com exceção da administração dos sacramentos que era reservada aos clérigos, a maior parte dos ofícios eclesiásticos poderia ser transmitida aos leigos pela via jurídica. Com isso, a possibilidade de admitir os leigos como juízes deveria ser ampliada, de modo que não fosse restrita à mera impossibilidade de se completar o colégio ${ }^{46}$.

2.1 Os leigos e o poder judicial na normativa do Código de Direito Canônico

Nos trabalhos de revisão do CIC, a Pontifícia Comissão debateu intensamente a problemática e os consultores tinham visões distintas sobre a amplitude ou menos da possibilidade de confiar a função judicante aos leigos. A formulação do cânon 126 do Schema canonum de 1977, discutido pelo Coetus de estudos De Normis Generalibus, afirmava que eram hábeis ao poder de jurisdição os que fossem «promovidos à Ordem sacra», enquanto os fiéis leigos poderiam «ter parte» no exercício do mesmo poder, enquanto «esta não se baseia na Ordem sacra», nos casos particulares em que fosse consentido pela Autoridade suprema ${ }^{47}$.

45 Cf. A. D'AURIA, I laici nel munus regendi in GRUPPO ITALIANO DOCENTI DI DIRITTO CANONICO (cur.), I laici nella ministerialità della Chiesa. Atti del XXVI Incontro di Studio Passo della Mendola (28 giugno - 3 luglio 1999), Milano 2000, 138-140.

46 Cf. A. D’AUria, I laici nel munus regendi, 141-143.

47 Pontificia Commissio Codici IURIS CANONici Recognoscendo, Coetus Studiorum "De normis generalibus". Sessio III [diebus 26 nov. - 1 dec. 1979 habita], in Communicationes, XXIII [1991], 219-220). 
Com o debate da Comissão dos Cardeais e Bispos em 1981, optou-se por uma via de conciliação entre as distintas posições: suprimiu-se o inciso que afirmava que o poder de jurisdição não se baseia na Ordem sacra, mantendo a possibilidade que os leigos pudessem cooperar no exercício desse poder ${ }^{48}$. De outro lado, a expressão «eam parte habere possunt» referida ao exercício do poder de jurisdição da parte dos leigos foi suprimida, para dar lugar à «cooperari possunt», de acordo com a linguagem de Lumen Gentium, n. 33.

A formulação definitiva do cânon 129 do CIC 1983 afirma que são hábeis para o poder de regime aqueles que foram promovidos à Ordem sacra. Os leigos, por sua vez, podem cooperar no exercício de tal poder, de acordo com as prescrições do direito ${ }^{49}$. Tal cânon, que admite a cooperação dos leigos no exercício da potestade de regime, não é facilmente harmonizável com o conteúdo do cânon 274, para o qual somente os clérigos podem obter ofícios, o qual exercício requer o poder de ordem.

Diante de tais dissonâncias, é mais útil partir não do poder de jurisdição e da sua origem, mas da diversidade dos ofícios. Os ofícios eclesiásticos, como bem definidos pelo cânon 145, consistem em «qualquer encargo constituído estavelmente, [...] a exercitar-se para um fim espiritual». Existem na Igreja, «ofícios e múnus laicais», distintos dos «múnus e ofícios estritamente clericais». Os ofícios estritamente reservados a quem detém a Ordem no grau do sacerdócio são aqueles que comportam a plena cura das almas ${ }^{50}$.

Quando se afirma que «somente os clérigos podem obter os ofícios que requerem a potestade de ordem ou a potestade de regime eclesiástico», em conformidade com o cânon $129 \S 1$, é possível afirmar que são hábeis a tais ofícios por instituição divina, dada a constituição hierárquica da Igreja. Isso não exclui que em casos especiais os leigos possam cooperar, quando idôneos e chamados dos sagrados

48 Cf. Pontificium Consilium De Legum TeXtis InTerpretandis, Congregatio Plenaria, 212.

49 Cf. IonnNes Paulus PP. II, Codex Iuris Canonici auctoritate Ioannis Pauli PP. II promulgatus, in AAS, LXXV (1983), II, 1-320, can. 129.

50 Cf. R. FunghINI, I laici nell'attività giudiziaria della Chiesa, in ARCISODALIZIO Della Curia Romana, I laici nel diritto della Chiesa, Città del Vaticano 1987, 124. 
Pastores, naqueles ofícios que não requerem como condição o sacramento da Ordem ${ }^{51}$.

No que diz respeito à constituição dos tribunais, a normativa do Código, no cânon $1421 \S 1$ explicitamente determina que os Bispos constituam juízes diocesanos clérigos. No entanto, o $\$ 2$ do cânon está em conformidade ao princípio segundo o qual os leigos podem cooperar com a função judicante que é parte da poder de jurisdição: afirmase que a Conferência Episcopal pode permitir que os leigos sejam constituídos juízes e que um deles possa ser assumido para constituir o colégio judicante.

Resultam, portanto, reducionistas as leituras segundo as quais os leigos exercem um poder delegado e não ordinário, ou que estes são apenas juízes extraordinários, ou meros cooperadores ${ }^{52}$. Não se pode concordar também com quem propõe que o titular do poder judicante não são os juízes singulares, mas o inteiro colégio, que exerceria em comum a potestade vicária em nome do Bispo ${ }^{53}$. Ainda, não é convincente a hipótese antes apresentada de admitir-se o juiz leigo para uma função de mera declaração de um fato, uma vez que a função judicial sempre produz nos seus destinatários um vínculo de sujeição obrigató$\mathrm{ria}^{54}$.

O exercício pessoal e ordinário do poder judicial da parte dos leigos não significa «exercício individual». $\mathrm{O}$ fato que o leigo receba o poder judicial do Bispo diocesano é suficiente para que se realize a cooperação proposta no can. 129 §2: o serviço do leigo juiz na Igreja não é ligado a quem recebeu em modo próprio a missão de agir governando a Igreja. Desse modo, é legítimo afirmar que o poder conferido ao juiz leigo é de natureza «integrativa», a ser exercitada somente como parte de um colégio judicante ${ }^{55}$.

51 Cf. R. FUNGHINI, I laici nell'attività giudiziaria, 124.

52 Cf. M. J. Arroba Conde, Diritto Processuale Canonico, Roma 2012, 96.

53 Cf. F. J. RAmos, I tribunali ecclesiastici, 113-114). Ver em contrário: M. J. ARROBA CONDE, Diritto Processuale Canonico, 204.

54 Cf. A. D'AURIA, I laici nel munus regendi, 145.

55 Cf. E. Kouveglo, I fedeli laici, 222; M. J. ArrobA CONDE, Diritto processuale canonico, 96. 
2.1.2 Os leigos no colégio judicante na normativa de Motu Proprio MIDI

O Motu proprio MIDI abre ulteriores espaços para a participação dos leigos na função judiciária, prevendo que possam ser a maioria no colégio judicante. Todavia, a questão sobre a titularidade ou a origem do seu poder judicial não vem totalmente resolvida. De um lado, propende para a afirmação da origem sacramental da potestade judicial, insistindo que a presidência do colégio deva ser exercida pelo membro clérigo. De outro lado, parece não afirmar a necessidade da Ordem para o exercício da função judiciária, quando permite que o colégio seja constituído em sua maioria por leigos ${ }^{56}$.

O fato de o Motu proprio não prever mais para as causas matrimoniais a permissão da Conferência episcopal ajuda a desfazer a impressão segundo a qual os leigos seriam meros suplentes por concessão, sem um vero e próprio poder judicial $^{57}$. A atribuição da função judicial aos leigos da parte dos Bispos ajuda a afirmar que os leigos possuem a plena capacidade para exercitar os ofícios relacionados à atividade judicial na Igreja.

A abertura mais ampla do Legislador em relação à participação dos leigos no ofício judicante reconhece que a atividade judiciária comporta uma série de operações de acertamento dos fatos, interpretação e decisão que requerem preparação e competência específicas, mais do que a qualificação em termos sacramentais ${ }^{58}$. A contribuição do leigo como juiz é constituída não apenas pela sua própria competência profissional, mas também porque este é portador de uma experiência social, e muitas vezes familiar e matrimonial que pode enriquecer notavelmente o exame da problemática relacionada ao vínculo conjugal $^{59}$.

56 Cf. P. A. TAVANI, I Laici e la funzione giudiziaria, in A.A. V.V., I soggetti del nuovo processo matrimoniale canonico, Città del Vaticano 2018,192.

57 Cf. P. MONETA, La funzione giudiziaria nella dinamica della potestà di governo della Chiesa in Aa. Vv., La giustizia nella Chiesa: fondamento divino e cultura processualistica moderna, Città del Vaticano 1997, 38.

58 Cf. P. MONETA, La funzione giudiziaria, 38.

59 Cf. P. A. TAVANI, I Laici e la funzione giudiziaria, 201). 


\section{Os juízos colegiais e a corresponsabilidade na decisão}

O Motu Proprio Mitis Iudex insiste em maneira preferencial para que as causas matrimoniais sejam tratadas por um colégio de três juízes. A nova normativa, portanto, continua seguindo substancialmente as motivações que já estavam na base na legislação do CIC 1983, para o exame das causas contenciosas mais difíceis. No CIC, como exposto, as causas que vertem sobre o estado de vidas das pessoas, sobre a existência ou menos de um sacramento, e sobre as penas canônicas mais graves são reservadas ao colégio judicante, porque dizem respeito ao interesse espiritual das pessoas e da comunidade eclesial $^{60}$.

A questão da conformação e da composição dos tribunais motiva certa discussão em doutrina, porque seja a forma monocrática como a forma colegial do órgão judicante apresentam ambas claras vantagens e desvantagens. Ramos e Carvajal afirmam sobre o juízo monocrático, ajuda a permitir uma maior divisão do tribunal em sessões (uma para cada juiz), acrescenta a possibilidade de servir-se dos auditores, reduz o problema do pessoal, favorecendo um trabalho mais direto da instrução da causa. Quanto à segurança e a certeza na administração da justiça, certamente o tribunal colegial oferece mais vantagens, por reduzir a influência dos aspectos subjetivos na decisão e por permitir o confronto de ideias e opiniões ${ }^{61}$.

O Legislador toma em consideração o fato de que as exigências de uma justiça atenta ao favor veritatis encontram uma maior garantia quando mais de uma pessoa contribui colegialmente com a decisão judicial. Por isso, as condições para a derrogação da obrigação da colegialidade nas causas matrimoniais são rigorosas: somente se permite o juízo monocrático no caso de real impossibilidade de se formar o colégio e apenas em primeiro grau de juízo ${ }^{62}$.

60 Cf. C. IzZI, Corresponsabilità e tribunali collegiali, in Apollinaris, LXXXII (2009), 268-269.

61 Cf. F. Ramos - D. M. Carvajal, Diritto processuale canonico, Roma 2013, 256.

62 Cf. C. IzzI, Corresponsabilità e tribunali collegiali, 269. 
No cânon 1426 CIC, afirma-se que o colégio deve proceder «colegialmente», o que significa que a sua modalidade de ação será aquela em que nos atos colegiais previstos no processo, decide-se pela maioria dos votos. O Presidente do colégio age como primus inter pares, é um colega com os demais membros do colégio, encarregado da presidência das sessões e da direção do processo, mas com voto par aos demais juízes ${ }^{63}$.

Com efeito, segundo Izzi, uma vez que são reservadas ao tribunal colegial as causas mais complexas e de maior relevância, este será a expressão mais representativa da corresponsabilidade eclesial no âmbito judiciário. O colégio envolve os juízes em uma dinâmica própria em que age o fator responsabilizante. A autora distingue tal fator em duas dimensões: um plano vertical, pois o juiz sentencia à luz da sua consciência, coram Domino, ou seja, tendo a Deus diante dos seus olhos; um plano horizontal, pois a responsabilidade dos juízes se explica no confronto com as partes em causa e toda a comunidade eclesial $^{64}$.

A dimensão horizontal da responsabilidade dos juízes no colégio exprime-se não apenas diante em dar as razões do próprio juízo diante das partes em causa, como também diante da comunidade eclesial. Se o primeiro dos deveres específicos do juiz nas causas matrimoniais é aquele de «render justiça», este não pode ser visto senão em uma perspectiva notadamente pastoral. A administração da justiça eclesial não pode tender senão para o fim próprio da Igreja, que é aquele de contribuir para o bem das almas ${ }^{65}$.

Importante reconhecer que a responsabilidade externa do colégio judicante em relação às partes e à comunidade eclesial parte de uma responsabilidade interna de cada um dos membros juízes com o inteiro órgão colegial. Isso quer dizer que o juiz na sentença colegial tem como interlocutores de um lado os colegas do colégio e de outro

63 Cf. C. IzZI, Corresponsabilità e tribunali collegiali, 272-273.

64 Cf. C. IzzI, Corresponsabilità e tribunali collegiali, 275.

65 Cf. A. Stankiewicz, I doveri del giudice, in P.A. BonNet - C. Gullo (curr.), Il processo matrimoniale canonico, Città del Vaticano 1994, 302. 
lado as partes públicas e privadas ${ }^{66}$. É oportuno advertir, de um lado para a tentação de desresponsabilização da parte de cada juiz, apoiando-se no trabalho e no contributo dos colegas. De outro lado, em contrário, aumentam as exigências sobre cada juiz, que deverá colaborar em modo paritário com os demais nas diversas funções e na emanação da sentença ${ }^{67}$.

O próprio Código ajuda a compreender a importância do contributo de cada juiz com a construção da decisão colegial. No cânon $1609 \S 1$, afirma-se que uma vez marcada a sessão decisória, cada um dos juízes deverá portar consigo as conclusões por escrito em relação ao mérito da causa, e as motivações em direito e em fato, a partir das quais é chegado às suas conclusões. Isso significa que cada juiz deverá expor aos demais as próprias opiniões, portar em luz a operação lógica que fez e que resultou no próprio escrito. $\mathrm{O}$ juiz deve apresentar a coerência do próprio modo de proceder, de modo a consentir que os demais interlocutores possam submeter a sua posição a uma avaliação crítica, partilhando ou rejeitando a decisão ${ }^{68}$.

Essa colaboração mútua e responsável de cada um dos juízes, analisando a quaestio facti e procurando a correspondência com a norma substantiva que possa dar a resposta à demanda feita ao colégio, é um contributo importante à objetividade da decisão ${ }^{69}$. A motivação da sentença será tanto mais adequada quanto resultar: da superação de toda forma de subjetivismo; na harmonização em senso objetivo, como resultado do convencimento de cada um dos juízes; na explicitação dos argumentos e da coerente interpretação dos fatos ${ }^{70}$.

O Código ainda tem em conta outra norma que ajuda a tutelar o verdadeiro sentido da colegialidade, contra todo errôneo convencimento subjetivo: o cânon $1609 \S 4$ permite que o juiz que não partilha da decisão tomada pela maioria dos membros do tribunal envie ao tri-

66 Cf. D. MOgAVERo, I pronunciamenti del giudice, in GRUPPO ITALIANO DoCENTI DI DIRITTO CANONICO (cur.), I giudizi nella Chiesa: il processo matrimoniale. Milano 1998, 176.

Cf. C. IzZI, Corresponsabilità e tribunali collegiali, 280-281.

. MOGAVERO, I pronunciamenti del gindice, $174-175$.

Cf. J. Llobel, La genesi della sentenza canonica in P.A. BONNET - C. GULlO, Il processo matrimoniale canonico, Città del Vaticano 1994, 718.

70 Cf. D. Mogavero, I pronunciamenti del giudice, 174. 
bunal superior também o seu próprio projeto motivado de sentença. Este seu voto não é um mero dissenso, mas servirá ao tribunal superior para que este tenha um quadro mais completo das opiniões dos juízes, em vista de uma possível revisão da decisão ${ }^{71}$.

Dessa maneira, o juízo colegial é um meio mais seguro em função do favor veritatis. O confronto entre as motivações dos juízes, a discussão, o compartilhamento das opiniões em vista da sentença, são as razões da preferência do Legislador por esta modalidade de juízo. A isso se acrescenta a possibilidade da participação dos leigos no colégio, enriquecendo o debate das questões afrontadas com a sua perspectiva, como demonstramos no título precedente.

\section{0 juízo monocrático e a formação dos assessores}

Por vários argumentos demonstrou-se que a colegialidade deve ser favorecida no tratamento das causas de nulidade matrimonial. O Legislador continua a favorecer tal possibilidade, quando condiciona a derrogação da colegialidade à real impossibilidade de formar-se um colégio composto por três juízes para tratar das causas matrimoniais (can. $1673 \S 4$ MIDI). Porém, um dos critérios fundamentais da reforma, como exposto, afirma a ampliação da possibilidade de recorrer ao juízo monocrático, possibilidade agora ligada à prudente avaliação de cada Bispo e não mais da Conferência episcopal.

O relaxamento normativo do can. $1673 \S 4$ MIDI, em relação ao can. $1525 \S 4$ CIC, não resulta difícil de ser interpretado, à luz dos princípios e finalidades principais da reforma. Não se ponha em dúvida que nas causas matrimoniais prevalecem o favor matrimonii e o favor veritatis. Todavia, o Legislador tem em vista uma justiça mais célere e acessível, que favoreça a proximidade das estruturas jurídicas e que seja marcada pela preocupação primordial do Bispo em oferecer o serviço judicial aos fiéis.

Como antes exposto, as principais vantagens do juiz único, é que este detém maior autonomia ao julgar, pode resolver a causa em modo mais célere, diminui-se o trabalho, diminuem-se os custos e o

71 Cf. J. Llobel, La genesi, 718; D. MogaVero, I pronunciamenti del giudice, 182. 
problema da disponibilidade de pessoal para a função judicante. Em termos de economicidade e acessibilidade do processo, bem como da proximidade do juiz em relação às partes, certamente o emprego do juízo monocrático resulta mais vantajoso ${ }^{72}$.

Vários autores, nos anos imediatamente precedentes à reforma, propunham a ampliação da aplicação do juiz monocrático, como uma das propostas para tornar o processo de nulidade matrimonial mais tempestivo e acessível. Llobel afirmava que o processo diante de um tribunal colegial requer necessariamente mais tempo. $\mathrm{O}$ acumular das funções num único juiz consente um melhor conhecimento das provas. Vem simplificada também a passagem entre uma e outra fase do processo, particularmente na fase de decisão e publicação da sentença. $\mathrm{O}$ recurso ao juiz único é uma solução onde pela falta de suficientes juízes, a colegialidade seja uma causa de frequentes atrasos na decisão dos processos matrimoniais ${ }^{73}$.

Recorde-se ainda, que, como aponta Arroba Conde, uma das questões mais significativas debatida em aula sinodal, durante a III Sessão Extraordinária do Sínodo dos Bispos, em 2014, foi sobre a possibilidade de confiar as causas a um juiz único. Tal posição se uniria à valorização da figura do Bispo, podendo fazer depender a constituição dos colégios judicantes monocráticos e não mais da Conferência episcopal, como previa o Código. Prudentemente, porém, dever-se-ia manter a colegialidade em segunda instância ${ }^{74}$.

A normativa resultante do MIDI atribui definitivamente ao Bispo moderador do tribunal constituído a função de confiar as causas ao juiz monocrático. No entanto, tal possibilidade está ligada a duas condições: que não seja possível constituir o tribunal colegial na diocese; e que nem mesmo no tribunal mais próximo diocesano ou interdioce-

72 Cf. F. Ramos - D. M. CARVAJal, Diritto processuale canonico, 256).

73 Cf. J. Llobel, La Pastoralità del complesso processo canonico matrimoniale: suggerimenti per renderlo più facile e tempestivo, in C. J. ERRÁZUIZ - M. A. ORTIZ (curr.), Misericordia e Diritto nel Matrimonio, Roma 2014, 137.

74 Cf. M. J. ARROBA CONDE, Le proposte di snellimento dei processi matrimoniali nel recente Sinodo, in L. SABBARESE (cur.), Sistema matrimoniale canonico in Synodo, Roma 2015, 75. 
sano a que o Bispo escolha de aceder (can. $1683 \S 2$ MIDI) seja possível constituir o colégio ${ }^{75}$.

Será o Bispo a considerar prudentemente as circunstâncias que determinem a impossibilidade da constituição do colégio, por certo período de tempo. Isso pode se dar quando não se conseguem obter os três juízes necessários; quando algum seja indisponível; quando seja inoportuno que um dos juízes assuma uma determinada causa; ou quando seja necessário, por exemplo, compensar grandes atrasos que impeçam o funcionamento normal do tribunal ${ }^{76}$. Quase sempre as causas serão de tipo pessoal, como a escassez de clero na diocese, quando não seja possível que haja ministros que se dediquem em modo prioritário à função judicial, a insuficiência de agentes formados, entre outras razões ${ }^{77}$.

Boni manifesta perplexidade em relação à nova norma, pois dada a penúria de pessoal que aflige uma grande parte das dioceses, é previsível uma multiplicação inconsequente de tribunais monocráticos. A autora, citando o antigo adágio «juiz único, juiz iníquo», teme que um juiz que não ponha em confronto com os pares competentes as suas opiniões e ideias, tenda facilmente a certa ligeireza na apreciação dos elementos que levem à certeza moral. $\mathrm{O}$ risco é ainda maior se se considera o fato da abolição da obrigação da dupla sentença conforme: a decisão do juiz em primeira instância dificilmente passará por uma revisão, para verificar a sua correção e aderência ao direito ${ }^{78}$.

Zambon expõe uma série de questões para a reflexão sobre o modo como os tribunais possam favorecer o bem dos fiéis e o direito dos mesmos a reivindicarem os próprios direitos na Igreja. Entre as indagações levantadas, manifesta-se a pergunta sobre o modo como seja possível garantir que haja ministros preparados a fornecer uma resposta competente a uma demanda apresentada por um fiel. O autor

75 Cf. R. R. SÁNCHEZ, Juez único, jueces laicos y asesores en el Motu Proprio «Mitis Iudex Dominus Iesus», in Revista Española de Derecho Canónico, LXXV (2018), 244.

76 Cf. P. Moneta, La dinamica processuale nel M. P. "Mitis Iudex", in Ius Ecclesiae, XXVIII (2016), 43; E. ZANETTI, Il ruolo del vescovo diocesano, 98-99.

77 Cf. R. R. SÁNCHEZ, Juez único, 243.

78 Cf. G. Boni, La recente riforma del processo matrimoniale. Problemi, criticità, dubbi in Stato, Chiese e pluralismo confessionale, XI (2016), 18-19. 
se interroga se o fato de aceder a um colégio unipessoal favorece uma resposta competente e preparada, tendo em vista a complexidade das causas matrimoniais e a necessidade de alcançar a certeza moral para emanar a sentença ${ }^{79}$.

\section{O papel dos assessores do juiz único}

A solução prevista pelo próprio Legislador para se prevenir, em qualquer modo, o possível subjetivismo, negligência ou arbitrariedade do juiz único, é que este, «onde seja possível, associe a si dois assessores de vida exemplar, especialistas em ciências jurídicas e humanas, aprovados pelo Bispo para esta função» (c. $1673 \S 4 \mathrm{MIDI})^{80}$.

A figura dos assessores, já era prevista no CIC e depois na Instrução Dignitas Conubii, mas ali não se indicavam explicitamente quais as suas funções, nem mesmo o tipo de formação ou requisitos exigidos para tal ofício (c. 1424; DC art. 52). Pode-se afirmar que o Motu Proprio sublinha alguns aspectos no sentido de reforçar a sua figura e melhorar tecnicamente a sua atuação no processo do ponto de vista jurídico e canônico ${ }^{81}$.

A função dos assessores consiste em auxiliar o juiz único e assisti-lo na qualidade de conselheiros. Exercem uma função meramente consultiva, sem poder exercitar a função propriamente judicial, mas o seu auxílio pode ser muito útil ao juiz em certas matérias que requeiram uma específica preparação ${ }^{82}$. O assessor poderá apenas esclarecer

79 Cf. A. ZAMBON, L'ordinamento giudiziario, in AA. V.V., La riforma del processo matrimoniale ad un anno dal Motu Proprio Mitis Iudex Dominus Iesus, Città del Vaticano 2017. 105-106.

80 Afirma Signorile: «La presenza dei due assessori rappresenta una garanzia sia pur minimale nei confronti di deprecabili arbitrii o inadempienze anche processuali del giudice unico». (E. SIGNORILE, Istruttore ed assessore in A.A V.V., I soggetti del nuovo processo matrimoniale canonico, Città del Vaticano 2018, 224).

81 Cf. R. R. SÁNCHEZ, Juez único, 260-261.

82 Cf. E. SigNORILE, Istruttore ed assessore, 220. 
o juiz sobre certos pontos ou aspectos específicos conforme sua competência $^{83}$.

Interessa-nos sublinhar que entre os critérios previstos pelo Legislador para os assessores do juiz monocrático é que, primeiramente sejam de vida exemplar. Esta compreende as mesmas qualidades gerais exigidas para exercer qualquer ofício eclesiástico, que são a comunhão com a Igreja e a idoneidade para a função (c. 228; c. 1424 CIC $)^{84}$. Os novos elementos são que os assessores sejam «especialistas em ciências jurídicas ou humanas», o que significa que devem distinguir-se pela competência nas matérias com as quais poderão auxiliar o juiz através dos seus conselhos ${ }^{85}$.

Para Sánchez, a nova previsão de que os assessores tenham várias especialidades amplia a gama das especialidades que podem ser úteis para auxiliar o juiz no desenrolar do processo. A expressão deve ser entendida como a pretensão de acentuar o caráter pastoral do processo e o caráter técnico e interdisciplinar com que devem ser tratadas as causas matrimoniais. A abertura para as ciências jurídicas é útil para resolver certas questões civis. O termo «ciências humanas», ainda que abarque a gama de ciências morais ou sociais, compreende as disciplinas sobre a saúde, a psicologia ou a filosofia ${ }^{86}$.

Boni adverte, porém, para a generalidade da norma: de um lado aponta para a variedade de especialidades dos consultores das quais o juiz possa ter necessidade (psicólogos, psiquiatras, terapeutas, mediadores familiares), de outro pode abrir a porta para que sejam admitidas pessoas sem qualquer qualificação. Ao menos um dos dois assessores deve ser dotado dos conhecimentos jurídicos canônicos, para evitar que considerações de natureza psicológica ou sociológica prevaleçam sobre as jurídicas. Afinal, o processo canônico é baseado em normas sobre a validade do matrimônio, cuja disciplina canonística é peculi$\operatorname{ar}^{87}$.

83 Cf. R. R. SÁNCHEZ, Juez único, 261. O autor adverte para os riscos de violação das normas canônicas e civis que a atuação ilegítima do assessor como perito poderia causar.

84 Cf. R. R. SÁNCHEZ, Juez único, 264.

85 Cf. E. SigNORILE, Istruttore e assessore, 221.

86 Cf. R. R. SÁNCHEZ, Juez único, 265.

87 Cf. G. BonI, La recente riforma, 20. 
Do mesmo parecer é Signorile afirma que é fundamental que o assessor tenha geralmente um bom conhecimento do direito canônico, em particular, do que se refere às causas matrimoniais ${ }^{88}$. Arroba Conde e Riondino afirmam que embora o assessor seja privo de potestade judicial, é útil para ajudar a evitar o risco de subjetivismo nas causas confiadas ao juízo monocrático. Tais autores lembram que tal exigência remete também ao cânon $212 \S 3$, segundo o qual, os leigos a são ouvidos pelos Pastores sagrados, no que se refere ao bem da Igreja, de acordo com a ciência, a competência, a preparação de que são investi$\operatorname{dos}^{89}$.

Deve representar uma garantia de qualidade e preparação em relação aos assessores, a previsão de que estes sejam «aprovados para o Bispo para esta função» (c. 1673 §4). Trata-se aqui, uma vez mais de relevar que o assessor desempenha uma função em nome da Igreja, ainda que nem sempre o faça em modo estável. Além disso, pode ser até desejável, que se forme um elenco de assessores para a intervenção em cada um dos processos de nulidade matrimonial, tendo em conta, que o Vigário judicial no decreto da fórmula da dúvida, poderá confiar a causa particular ao juiz único, onde isso for necessário (c. 1676 $\S 3)^{90}$.

A norma sobre o juízo monocrático no MIDI faz menção à carência em tal modo acentuada de pessoas preparadas até mesmo para o labor de assessores, seja para a falta de pessoas formadas ou pela impossibilidade de contar com as mesmas em modo eventual ou fixo ${ }^{91}$. Por isso, prevê que «onde for possível» o Juiz seja assistido por dois assessores. Se, como referimos, a função do assessor representa uma garantia mínima contra a arbitrariedade ou a negligência do juiz, o grande desafio é que quanto antes seja garantido um mínimo de formação canônica a quem possa servir aos tribunais ${ }^{92}$.

A recente Instrução da Congregação para a Educação Católica sobre os estudos de Direito Canônico (29 de abril de 2018) pretende

88 Cf. E. SignORILE, Juez único, 208 e 221.

89 Cf. M. J. ARROBA CONDE - M. RIONDINO, Introduzione al diritto canonico, Città di Castelo 2017, 195.

90 Cf. R. R. SÁNCHEZ, Juez único, 266.

91 Cf. R. R. SÁNCHEZ, Juez único, 264.

92 Cf. E. SigNORILE, Istruttore ed assessore, 224. 
encorajar as Instituições acadêmicas eclesiásticas a oferecer currículos de estudo para formar canonistas e consulentes qualificados. A proposta nova prevista é que tais Instituições possam oferecer um currículo de estudos, com duração de pelo menos um ano acadêmico, para o conseguimento de um Diploma em Direito Matrimonial e Processu$\mathrm{al}^{93}$. Tal Diploma consistirá em uma habilitação para que os operadores desempenhem aqueles ofícios no tribunal que não requeiram o título do Mestrado ou Doutorado em Direito Canônico, entre os quais o ofício de assessor.

A difusão dessa proposta, com percursos formativos canônicos simplificados em relação ao que se requer para a obtenção dos títulos acadêmicos, representa um dos meios concretos para remediar a escassez de pessoal preparado nas dioceses. Tudo isso tem em vista, as determinações do MIDI, o qual pede que nas dioceses sem um tribunal próprio, o Bispo cuide formá-lo, mediante cursos de formação permanente e contínua para preparar os seus agentes. Tais cursos podem ser promovidos pelas dioceses, ou por seus agrupamentos, ou ainda pela Sé Apostólica, de modo que as pessoas possam prestar o seu serviço aos tribunais ${ }^{94}$.

\section{Conclusão}

A constituição dos tribunais diocesanos para as causas matrimoniais na disciplina do Motu proprio Mitis Iudex Dominus Iesus apresenta algumas inovações normativas importantes em relação ao Código de Direito Canônico. A reforma dos processos de nulidade matrimonial é toda orientada a fazer com que a administração da justiça nos tribunais eclesiásticos seja mais acessível e célere, de modo a favorecer o bem dos fiéis. Estes têm direito a ver esclarecida a própria situação ou a possível nulidade do matrimônio, em modo simples e em tempo razoável.

\footnotetext{
93 Congregazione Per l'EducAzione CATtolicA, Istruzione: Gli studi di Diritto Canonico alla luce della riforma del processo matrimoniale, Città del Vaticano 2018, art. 12-17.

94 FranCISCUS PP., Mitis Iudex, Ratio Procedendi, art. 8.
} 
Uma das causas mais evidentes da lentidão dos processos, ou ainda da sua pouca acessibilidade aos fiéis é, certamente, a falta de agentes preparados para desempenhar a função judicial nas dioceses ou a sua insuficiente preparação. A recente reforma, em resposta, solicita aos Bispos maior atenção pastoral à realização dos processos, e pede que se dê prioridade à constituição dos tribunais diocesanos e à preparação dos seus juízes e agentes.

A normativa do cânon 1673 MIDI parte do princípio de que na sua diocese o próprio Bispo é juiz, mas pode confiar a função judicial a outros juízes. O Motu proprio pede a constituição dos tribunais diocesanos para favorecer a proximidade do serviço judicial aos fiéis. $\mathrm{O}$ Bispo pode aceder a um tribunal vizinho, ou ainda a um tribunal interdiocesano, desde que tal opção favoreça o tratamento célere das causas ou quando não se possa constituir os órgãos judicantes no âmbito diocesano. A normativa, no entanto, pede em modo prioritário que sejam constituídos os tribunais na diocese com juízes devidamente formados.

O Motu proprio insiste para que as causas matrimoniais sejam tratadas em modo preferencial por um colégio de três juízes. No $\S 4$ do cânon 1673, porém, permite-se que na impossibilidade de constituir o tribunal colegial ou aceder a um tribunal vizinho, que as causas sejam confiadas a um juiz único. A inovação normativa importante aqui é que a atribuição das causas ao juiz monocrático depende unicamente da decisão do Bispo, sem depender mais da autorização da Conferência episcopal.

Ao longo do texto preferimos manter distinta a noção de «tribunal» enquanto estrutura judiciária, de «órgão judicante» enquanto turno colegial ou juiz único (acompanhado por assessores) a quem são confiadas as causas. $\mathrm{O}$ vocábulo empregado em um outro caso é o mesmo no cânon 1673 MIDI - «tribunal» - o que pode sugerir a ideia de que seja possível a um Bispo constituir um tribunal na sua diocese formado por apenas um juiz. Todavia, parece mais aceitável a opinião segundo a qual o Bispo possa somente confiar as causas a um juiz único e em circunstâncias excepcionais, quando da impossibilidade em se formar o colégio. 
O que pode favorecer a constituição do colégio judicante é que agora se permite que este seja formado por dois leigos e um clérigo. Procuramos demonstrar que a inclusão dos leigos no colégio é problemática para certa doutrina que associa a função judicial estreitamente ao poder sacramental da Ordem. No entanto, a previsão do Motu proprio é coerente com o princípio codicial segundo o qual os leigos podem cooperar no exercício do poder de jurisdição dos ministros ordenados. Se o poder de julgar é exercitado em modo ordinário mesmo pelos leigos, nada impede que possam ser a maioria no colégio, contribuindo com a sua válida experiência formativa e pessoal às decisões judiciais.

O Legislador mantém a preferência pela atribuição das causas ao juízo colegial, pois este permite maior objetividade, corresponsabilidade e qualidade às decisões mediante o confronto crítico de ideias no voto de cada um dos juízes. Neste sentido, a atribuição das causas a um juiz único, continua a ser prevista em modo excepcional, ainda que seja facilitada pela nova normativa do cânon 1673 MIDI. Se é suficiente a autorização do Bispo, é necessário, no entanto, fazer atenção para que o amplo uso do juízo monocrático não comprometa a qualidade na administração da justiça.

A figura dos assessores, os quais não votam a sentença, mas prestam um auxílio importante à decisão, torna-se importante quando a possibilidade do juízo monocrático vem ampliada. Os critérios previstos para a admissão destes, ou seja, que sejam de vida íntegra ou peritos em ciências jurídicas ou humanas, não podem prescindir de uma formação canonística suficiente, dada a natureza dos processos de nulidade matrimonial.

É preciso sublinhar, no entanto, que o risco de laxismo a ser evitado unido à prevalência da colegialidade que garante a maior qualidade nos juízos, faz com que os Bispos tenham como meta a medida mais alta na formação de ministros para os ofícios judicantes. O Sínodo dos Bispos de 2015 afirmava na conclusão dos trabalhos a necessidade de preparar mais pessoas com dedicação prioritária ao serviço judicial $^{95}$. Portanto, não se pode permitir que a exceção se torne a re-

95 «L'attuazione di questi documenti [i Motu Proprio] costituisce dunque una grande responsabilità per gli Ordinari diocesani, chiamati a giudicare loro stessi alcu- 
gra. Por difícil que ainda seja tal objetivo em tantas realidades, é fundamental dar passos para a sua concretização, tendo em conta a importância fundamental do serviço da justiça na vida da Igreja.

\section{Bibliografia}

\section{Fontes}

Concilium OeCumenicum VATICANUM II, Costitutio dogmatica de Ecclesia: Lumen Gentium, in AAS, LVII (1965), 5-75.

CONGREgazIONE PER L'EduCAZIONE CATTOLICA, Istruzione: Gli studi di Diritto Canonico alla luce della riforma del processo matrimoniale, Città del Vaticano 2018.

Franciscus PP., Saluto del Santo Padre Francisco ai partecipanti al Corso Super rato promosso dal Tribunale della Rota Romana $(5$ novembre 2014), in Quaderni dello Studio Rotale XXII (2015), 61-62.

FrANCISCUS PP., Litterae Apostolicae motu proprio datae quibus Canones Codicis Iuris Canonici de Causis ad Matrimonii nullitatem reformantur: Mitis Iudex, in AAS, CVII (2015), 958-970.

IoAnnes Paulus PP. II, Codex Iuris Canonici, auctoritate Ioannis Pauli PP. II promulgatus, in $A A S$, LXXV (1983), II, 1-320.

Pontificia Commissio Codici Iuris CANONici ReCognoscendo, Coetus Studiorum "De normis generalibus". Sessio III (diebus 26 novembris - 1 decembris 1979 habita), in Communicationes, XXIII (1991).

Pontificium Consilium de Legum TeXTis InTERPRETANDis, Acta et Documenta Pontificiae Commissionis Codicis Iuris Canonici

ne cause e, in ogni modo, ad assicurare un accesso più facile dei fedeli alla giustizia. Ciò implica la preparazione di un personale sufficiente, composto di chierici e laici, che si consacri in modo prioritario a questo servizio ecclesiale» (SYNODUS EPISCOPORUM, Coetus generalis XIV. Relatio finalis, in AAS CVII [2015], 1161-1221, n. 82). 
Recognoscendo. Congregatio Plenaria. Diebus 20-29 octobris 1981 habita, Città del Vaticano 1991.

Pontificium Consilium De Legum TeXTiBus, Instructio servanda a Tribunalibus dioecesanis et interdioecesanis pertractandis Causis Nullitatis Matrimonii: Dignitas Conubii, in Communicationes, XXXVII (2005), 11-92.

SyNODUS EPISCOPORUM, Os desafios pastorais sobre a família no contexto da evangelização. Documento preparatório, Cidade do Vaticano 2013, in URL: <http://www.vatican.va/roman_curia /synod/documents/rc_synod_doc_20131105_iiiassembleasinodo vescovi_po.html> (in 16/02/2019).

SYNODUS EPISCOPORUM, Le sfide pastorali sulla famiglia nel contesto dell'evangelizzazione. Instrumentum laboris, Città del Vaticano 2014.

SynOdUS EPISCOPORUM, Coetus generalis XIV. Relatio finalis, in $A A S$, CVII (2015), 1161-1221.

\section{Literatura}

Arroba Conde M. J., Diritto processuale canonico, Roma 2012.

ARroba Conde M. J., Le proposte di snellimento dei processi matrimoniali nel recente Sinodo, in L. SABBARESE (cur.), Sistema matrimoniale canonico in Synodo, Roma 2015.

Arroba Conde M. J. - Riondino M., Introduzione al diritto canonico, Città di Castelo 2017.

Arroba Conde M. J., Presentazione dell' "Istruzione" della Congregazione per l'Educazione Cattolica: Gli studi di Diritto Canonico alla luce della riforma del processo matrimoniale, Città del Vaticano 2018.

Boni G., La recente riforma del processo matrimoniale. Problemi, criticità, dubbi, in Stato, Chiese e pluralismo confessionale, XI (2016). 
Bunge A. W., Presentación del nuevo proceso matrimonial, in URL: $<$ http: //www.awbunge.com. ar/AADC2015.pdf $>$ (in 01/04/2019).

CHACÓN R. R., Antecedentes, estructura y valor jurídico en el sistema normativo canónico de los dos motu proprio de 15 agosto de 2015 y sus normas anejas in M. E. Olmos OrTEGA (ed.), Procesos de nulidad matrimonial tras la reforma del Papa Francesco, Madrid 2016.

Coccopalmerio F., Processo matrimoniale e missione della Chiesa, in Aa. Vv., La riforma del processo matrimoniale ad un anno dal Motu Proprio Mitis Iudex Dominus Iesus, Città del Vaticano 2017.

D'Auria A., I laici nel munus regendi in GRUPPO ITALIANO DOCENTI DI DiRITTO CANONICO (cur.), I laici nella ministerialità della Chiesa. Atti del XXVI Incontro di Studio Passo della Mendola (28 giugno - 3 luglio 1999), Milano 2000.

Del Pozzo M., Dal "Tribunale limitrofo" al "tribunale sussidiario”: una proposta di miglior sistemazione concettuale della nozione, in J. KowAL - J. Llobel (curr.), "Iustitia et iudicium». Studi di diritto matrimoniale e processuale canonico in onore di A. Stankiewicz, Città del Vaticano 2010.

Del Pozzo M., L'organizzazione giudiziaria alla luce del m.p. "Mitis Iudex", in Stato, Chiese e pluralismo confessionale, XXXVI (2015).

Del Pozzo M., Chiarimenti pontifici sul "processus brevior”. Riflessione alla luce del Discorso del 25 novembre 2017, in Ius Canonicum, LVIII (2018).

FUNGHINI R., I laici nell'attività giudiziaria della Chiesa, in ARCISODALIZIO DELla CURIA RomAnA, I laici nel diritto della Chiesa, Città del Vaticano 1987.

GORDON I., De nimia processuum matrimonialium duratione, in Periodica de re morali canonica liturgica, LVIII (1969). 
IzzI C., Corresponsabilità e tribunali collegiali, in Apollinaris, LXXXII (2009).

IzZI C., Identità e ruolo dei laici nella comunione ecclesiale in GRUPPO ITALIANO DOCENTI DI DIRITTO CANONICO (cur.), La comunione nella vita della Chiesa: le prospettive emergenti del Vaticano II, Milano 2015.

Kouveglo E., I fedeli laici e l'esercizio della potestà nella Chiesa. Status quaestionis e ricerca di una chiave funzionale di lettura, in Apollinaris, LXXXX (2017).

Llobel J., La genesi della sentenza canonica, in P.A. BonNET - C. Gullo, Il processo matrimoniale canonico, Città del Vaticano 1994.

Llobel J., La Pastoralità del complesso processo canonico matrimoniale: suggerimenti per renderlo più facile e tempestivo, in C. J. ERRÁZUIZ - M. A. ORTIZ (curr.), Misericordia e Diritto nel Matrimonio, Roma 2014.

Mogavero D., I pronunciamenti del giudice, in GruPPO ItALIANO DOCENTI DI DIRITTO CANONICO (cur.), I giudizi nella Chiesa: il processo matrimoniale, Milano 1998.

Moneta P., La funzione giudiziaria nella dinamica della potestà di governo della Chiesa, in AA. Vv., La giustizia nella Chiesa: fondamento divino e cultura processualistica moderna, Città del Vaticano 1997.

Moneta P., La dinamica processuale nel M. P. "Mitis Iudex", in Ius Ecclesiae, XXVIII (2016).

Montini G. P., La prassi delle dispense da leggi processuali del Supremo Tribunale della Segnatura Apostolica (Art. 124, N. 2, $2^{a}$ Parte, Cost. Ap. Pastor Bonus), in Periodica de re canonica, XCIV (2005).

Peña García C., El proceso ordinario de nulidad matrimonial en la nueva regulación procesal, in M. E. Olmos ORTEGA (ed.), Procesos de nulidad matrimonial tras la reforma del Papa Francesco, Madrid 2016. 
PINTO P. V., La riforma del processo matrimoniale per la dichiarazione di nullità voluta e decisa da Papa Francesco, in Quaderni dello Studio Rotale, XXIII (2016).

Pompedda M. F., Il giudice ecclesiastico, in Quaderni dello Studio Rotale, XXIII (2016).

Ramos F. J., I tribunali ecclesiastici. Costituzione, organizzazione, norme processuali, Roma 1996.

Ramos F. J. - Carvajal D. M., Diritto processuale canonico, Roma 2013.

Rodrigo R., Cur Optata A.M.P. "Causas matrimoniales" celeritas haud semper obtinetur?, in Periodica de re morali canonica liturgica, LXII (1973).

SABBARESE L., Semplicità e celerità nel processo matrimoniale canonico, in P.A. BONNET - C. Gullo, Il giudizio di nullità matrimoniale dopo l'Istruzione "Dignitas Conubii", Città del Vaticano 2007.

SÁNCHEZ R. R., Juez único, jueces laicos y asesores en el Motu Proprio «Mitis Iudex Dominus Iesus», in Revista Española de Derecho Canónico, LXXV (2018).

SignORILE E., Istruttore ed assessore, in A.A V.V., I soggetti del nuovo processo matrimoniale canonico, Città del Vaticano 2018.

StAnkiewiCz A., I doveri del giudice, in P.A. BonNET - C. Gullo (CURR.), Il processo matrimoniale canonico, Città del Vaticano 1994.

TAVANI A. P., I Laici e la funzione giudiziaria in A.A. V.V., I soggetti del nuovo processo matrimoniale canonico, Città del Vaticano 2018.

ZAMBON A., L'ordinamento giudiziario: il tribunale di prima istanza in AA. VV., La riforma del processo matrimoniale ad un anno dal Motu Proprio Mitis Iudex Dominus Iesus, Città del Vaticano 2017. 
A COMPOSIÇÃO DOS TRIBUNAIS DIOCESANOS NA REFORMA DOS PROCESSOS DE NULIDADE MATRIMONIAL

ZANETTI E., Il ruolo del vescovo diocesano in REDAZIONE DEI QUADERNI DI DIRITTO ECCLESIALE (cur.), La riforma dei processi matrimoniali di Papa Francesco. Una guida per tutti, Milano 2016. 